\title{
»Aufschluss« und »Knast - Ich? - Nie!« Ein Filmprojekt und eine Broschüre zum Film
}

\author{
Gabriele Kawamura-Reindl
}

Mitarbeiter im Strafvollzug behaupten, eine Überfüllung der Gefängnisse lasse sich am ehesten dadurch vermeiden, wenn man Richtern und Staatsanwälten die Haftbedingungen vor Ort zeige. Da sich aber nicht jeder über den Strafvollzug in Deutschland durch den Besuch einer Haftanstalt einen unmittelbaren Eindruck über die Gefängnisrealität verschaffen kann - Justizvollzugsanstalten sind schließlich keine Zoo und kein Museum - und eine unmittelbare Anschauung nur wenigen Besuchern möglich ist, wollen die Mitarbeiter des Kölner Vereins Maßstab e.V. zumindest einen filmischen Einblick gewähren und haben mit dem von Karl Peter Rotthaus, Präsident des Justizvollzugsamt Rheinland a.D. angeregten Projekt KIN- (»Kriminalprävention durch Ein-Sicht «) dies in die Tat umgesetzt. Sie zeigen, welche Menschen sich dort aufhalten müssen und wie sie die Einsperrung und die damit einhergehenden Beschränkungen und Gegebenheiten erleben. Adressaten sind v.a. Jugendliche in Schulen und Jugendzentren, die den Vollzug häufig eher romantisieren, aber auch andere Zielgruppen: Lehrer, Sozialpädagogen, (angehende) Juristen, v.a. Richter, Staatsanwälte und andere Berufsgruppen, die mit jungen Menschen befasst sind sowie ehrenamtliche Mitarbeiterinnen im Vollzug.

Der vor allem von den Medien immer wieder verbreiteten Mär vom »Hotelvollzug « setzt der dreiviertelstündige Film von Holger Löchner die eher bedrückende Realität des Jugendvollzuges entgegen. Vorsätzlich verzichtet er darauf, die pädagogischen Segnungen des Jugendvollzuges $\mathrm{zu}$ preisen, die - wie Untersuchungen zeigen - ohnehin nur einem geringen Teil von Jugendlichen zugute kommen und in der Jugenduntersuchungshaft sowieso nicht greifen. In dem Film wird die authentische Realität zweier Jugendlicher - bewusst aus deren Sicht - dargestellt. Die beiden Jugendlichen schildern den tristen Vollzugsalltag und die Schwierigkeiten, mit der Haftsituation und der damit verbundenen Isolation zurecht zu kommen. Einer der beiden, der 17 jährige Dirk, gerät zum ersten Mal in Untersuchungshaft. Im Film schildert er einen mit persönlichen Belastungen und Drogenkonsum verbundenen Lebensabschnitt, der mit seiner Straftat beginnt und sich mit der Verhängung von Untersuchungshaft sowie einer Betreuung durch Mitarbeiter der Straffälligenhilfe fortsetzt. Andreas, der andere Jugendliche, hat schon einschlägige Erfahrungen mit dem Vollzug und zählt - im Film sagt er es selbst - eher zu einer schwierigen Klientel. Die Schilderung seiner persönlich empfundenen Ausweglosigkeit macht deutlich, welche Anstrengungen im Vollzug wie außerhalb des Vollzuges unternommen werden müssten, um solchen Jugendlichen eine tatsächliche
Chance zur Wiedereingliederung zu bieten.

Realistisch über den Vollzug informieren will nicht nur der Film, sondern auch das dazu gehörende Begleitheft. Die 64seitige Broschüre von Helmut Geiter gibt Erläuterungen zum Anliegen und Entstehen des Films »Aufschluss«. Darüberhinaus liefert sie zusätzliche Informationen zum Thema Strafverfahren, Strafvollzug und zur Situation von Gefängnisinsassen. Sie greift Fragen auf, die den Mitarbeitern nach probeweisen Vorführungen des Films häufiger gestellt wurden. In erster Linie dient die Broschüre dazu, denjenigen, die den Film als Arbeitsmaterial einsetzen, eine bessere Orientierung zum Thema Strafvollzug zu ermöglichen.

Ob der Film tatsächlich bei der jugendlichen Zielgruppe einen Beitrag zur Kriminalprävention leisten kann, sei dahin gestellt. Die Autoren verweisen selbst auf die Schwierigkeiten, kriminalpräventive Effekte nachzuweisen. Aber er trägt in jedem Fall zur Diskussion über fest gefügte Vorurteile bei und zwingt, sich mit der Realität des Vollzuges auseinanderzusetzen, dessen Entwicklung noch weit entfernt ist von den Wunschvorstellungen der Väter des Strafvollzugsgesetzes und den Zielen eines für alle Jugendlichen pädagogisch ausgestalteten Behandlungsvollzugs. Damit verfolgen der Film und die Broschüre in Zeiten knapper Kassen und schwindender gesellschaftlicher Resozialisierungsbereitschaft auch kriminalpolitische Intentionen.

Der Film macht noch ein anderes deutlich: Die Resozialisierung von straffällig Gewordenen lässt sich nicht nur denen aufbürden, die sich beruflich - sozusagen zwangsläufig - als Richter, Sozialpädagogen, Therapeuten oder Vollzugsbedienstete mit diesem Personenkreis zu befassen haben. Auch wenn diese Personen (-gruppen) im Rahmen ihres beruflichen Auftrages eine besondere Verantwortung für die Resozialisierung der Betroffenen tragen, nehmen sie letztlich einen gesellschaftlichen Auftrag wahr, den auch die Allgemeinheit mittragen muss. Der Film und die Broschüre können einen Beitrag dazu leisten, zwischen Vollzug und Gesellschaft eine Brücke zu schlagen.

Den Film »Aufschluss« und die dazu gehörende Broschüre gibt der Verein Maßstab e.V. kostenlos an Interessenten $a b$. Beides kann bestellt werden bei Maßstab e.V., Verein für eine soziale Zukunft, Projekt KIN, Luxemburger Str. 190, 50937 Köln. Gezeigt werden darf der Film allerdings nur unter einer Bedingung: Für die zum Projektkonzept gehörende Diskussion mit den Zuschauern muss ein Experte/eine Expertin aus dem (Jugend-)Strafvollzug oder der sog. (Jugend-)Strafrechtspflege zur Verfügung stehen. Außerdem wird das Ausfüllen eines Rückmeldebogens (15 Fragen) erwartet. 